\title{
A HISTÓRIA DA POESIA BRASILEIRA DE ALEXEI BUENO
}

\author{
THE HISTORY OF BRAZILIAN POETRY BY ALEXEI BUENO
}

Bruno Marques Duarte ${ }^{1}$

\section{Resumo}

A partir das teorias da historia da literatura, busca-se, neste artigo, analisar os critérios que compõem a escrita de Uma história da poesia brasileira, de Alexei Bueno. Objetiva-se, também, examinar os conceitos de "poesia" e "história" concebidos pelo autor, bem como o eixo norteador em que se organizam a narrativa, a classificação dos períodos literários, e o(s) método(s) crítico(s) utilizado(s) na obra.

Palavras-chave: história, poesia, literatura brasileira, Alexei Bueno.

\begin{abstract}
Based on the theories of literary history, this paper analyzes the criteria that constitute the book $A$ history of brazilian poetry, by Alexei Bueno. The purpose is also to examine the concepts of "poetry" and "history" created by the author as well as the guiding principle in which are organized the narrative, the classification of literary periods, and the critical methods used in the work.
\end{abstract}

Keywords: history, poetry, Brazilian literature, Alexei Bueno.

\section{Considerações preliminares}

Este artigo analisa a composição de Uma história da poesia brasileira, publicada em 2007, de - primeiro poeta, depois historiador - Alexei Bueno. A partir das teorias da história da literatura, essa proposta de exame do discurso historiográfico tem como objetivo apontar as possíveis inovações que a obra apresenta, e em que medida essa reconstituição do passado literário contribui para o estabelecimento de uma nova memória da poética brasileira.

No decorrer da pesquisa, busca-se depreender os conceitos de “poesia” e "história” subjacentes ao texto; o eixo norteador a partir do qual se organiza a narrativa; a classificação dos períodos literários; o cânone estabelecido, e o perfil que assume a crítica literária do historiador. Em síntese, procura-se constatar se a obra Uma história da poesia brasileira, de Alexei Bueno, revela-se como uma proposta inovadora no âmbito da escrita da história da literatura brasileira.

\footnotetext{
${ }^{1}$ Doutorando pela Universidade Federal do Rio Grande - FURG - Instituto de Letras e Artes. Programa de PósGraduação em Letras - História da Literatura. Email: brunomd@hotmail.com
} 
Dado que toda a escrita científica é sempre permeada de um referencial teórico, e este é sempre uma escolha arbitrária do pesquisador autor, não mencionamos nesse artigo todas as vertentes teóricas que refletiram e que atualmente pensam o processo de elaboração das historiografias literárias, isso tornaria o trabalho muito extenso. Portanto, selecionamos somente os teóricos que consideramos fundamentais para o exame de qualquer obra que se propõe a ser uma história da literatura.

O título Uma história da poesia brasileira da obra de Alexei Bueno contempla duas premissas importantes a propósito das histórias literárias. Primeiro, a palavra Uma evidencia a consciência do autor de que o processo de elaboração das historiografias literárias é seletivo, e "ser a narrativa do passado seletiva e lacunar não significa que seja falsa, porque se admitimos isso, o único relato fiel do passado seria o próprio passado, e não o veríamos como história” (PERKINS, 1999, p. 9). Desta forma, Bueno não se torna prepotente em sua História, deixando a possibilidade para que outros também escrevam a partir de uma lente diferente da sua. A segunda premissa refere-se à palavra poesia, que revela o protagonista dessa história, isto é, um gênero literário específico, o lírico. Sendo assim, o título dessa história da literatura revela-se inovador na esfera das histórias literárias brasileiras.

\section{O prefácio}

Em tese, a apresentação de um prefácio - ou introdução - nas histórias da literatura constitui um dos principais elementos que possibilita uma melhor organização e compreensão dessas obras. Além disso, essa exigência consiste em trazer para a produção histórica, seja ela literária ou não, critérios que demarcam a natureza científica da escrita dos historiadores. Uma introdução é eficiente, na medida em que o leitor tem clareza dos conceitos que orientam a arbitrariedade do pesquisador-autor, assim, sua escrita historiográfica torna-se plausível ao dirigir um olhar justificado para o passado. Conforme aponta Tynianov, “o ponto de vista adotado determina o tipo de estudo histórico” (TYNIANOV, 1973, p. 106).

No âmbito das histórias literárias brasileiras, algumas contemplam uma introdução hábil, outras não. Por exemplo, Antonio Candido, em Formação da literatura brasileira: momentos decisivos escreve uma introdução teórica intitulada "Literatura como sistema”, em que fundamenta sua perspectiva para narrar o amplo passado literário. Já na obra de Alfredo Bosi, História concisa da Literatura brasileira, verifica-se o contrário, Bosi inicia com o capítulo “situação colonial”, transferindo para o leitor identificar - ou não - o pensamento teórico e os conceitos que permeiam a referida narrativa histórica. 
Conforme Perkins (1999, p. 1), a história literária se constitui a partir de categorias da narrativa, esta descreve "a transição, através do tempo, de um estado de coisas a outro diferente, e um narrador nos conta essa mudança” ao escolher um protagonista (herói). Alexei Bueno (2007, p. 9) no prefácio de Uma história da poesia brasileira reflete sobre as possíveis definições de poesia. Baseando-se no poema La moneda de hierro, 1976, de Jorge Luis Borges, Bueno elabora pela metalinguagem duas definições parciais que se completam para conceituar poesia: “diz a primeira: a poesia é uma indecisão entre um som e um sentido”, e "a segunda: a poesia é a arte de dizer com as palavras o que apenas as palavras não podem dizer”. Em seguida, o autor complementa sua definição ao expressar que "toda obra de arte verbal plenamente realizada [...] que é a palavra, algo se constrói que não nasce dela, apenas dela se utiliza, e a transcende largamente”. Essa definição apresenta teoricamente o protagonista da história da literatura de forma satisfatória e eloquente, cumprindo com a premissa conceitual mencionada acima referente às introduções.

Seguindo, Bueno (2007, p. 10) discute sobre as limitações que a crítica e a teoria da literatura têm para analisar os fenômenos estéticos que a arte possibilita no sujeito receptor. Afirma o autor que "a primeira exigência de toda crítica séria é a limitação ao mínimo das idiossincrasias pessoais, já que a sua eliminação é impossível”. Portanto, Bueno aponta que “tudo em arte, no limite das possibilidades, é compreensão impressionista”. No entanto, Bueno justifica a seriedade do trabalho em estabelecer que "o que buscamos neste livro é justamente traçar uma linha histórica da poesia brasileira com o mínimo de idiossincrasias, e com uma visão aguda de cada autor dentro de sua própria visão de mundo, sua época e estilo” (BUENO, 2007, p. 11). Segundo Bueno,

\begin{abstract}
há simplificações nefastas na percepção vulgar da literatura e das outras artes no Brasil. A pior delas, sem dúvida, é fruto da ideologia do progresso, essa noção da história e da humanidade como uma superação perene que invadiu o Ocidente a partir do século XVIII. Levada ao domínio da arte, tal postulação é das mais desastrosas, criando a ilusão de que o mais recente é sempre superior ao anterior, visão muito fortalecida pela vivência cotidiana do capitalismo tecnológico que é a nossa, no qual, inclusive com certa obsolescência programada, os bens de consumo se superam e se eliminam em rapidez cada vez mais vertiginosa. A questão é que um poema, uma sinfonia, uma pintura, uma igreja, não são celulares ou geladeiras, cada vez mais rapidamente atropeladas por seus congêneres da "última geração." (BUENO, 2007, p. 11).
\end{abstract}

Em tempos de apagamento do passado e de viver o eterno novo, rever é fundamental para não se fazer tábula rasa das experiências artísticas. Conforme Jameson, o tempo pósmoderno tornou-se “uma tentativa de pensar historicamente o presente em uma época que já 
se esqueceu de como pensar dessa maneira” (JAMESON, 1997, p. 13). Isto é, a perda da historicidade. Este problema se agrava com a concepção de história revestida de progresso. Bueno objetiva superar essa concepção, e a partir disso, narrar o fenômeno literário da poesia na sua historicidade. Evidentemente, a reconstrução do passado nunca é de fato como ele realmente se sucedeu. A concepção idealista historicista do século XIX postulava essa pretensão. Porém, a história se torna viva justamente pela consciência que o presente possui ou não do passado. Portanto, as obras de arte, assim como a própria História, se renovam e se reconstituem na medida em que o tempo presente pensa sobre si mediante as várias leituras possíveis do passado (BARRENTO, 1986, p. 9).

Perkins aponta que "os possíveis enredos de histórias narrativas da literatura podem ser reduzidos a três: ascensão, declínio e ascensão e declínio” (1999, p. 13). O enredo proposto por Bueno, em termos de estética, é “idéia de um tempo cíclico, um eterno retorno entre o apogeu e a decadência, entre a idade de ouro e a de ferro, que de fato rege a movimentação circular da expressão artística” (2007, p. 11). Portanto, o enredo apresenta-se vinculado a uma perspectiva temporal de ascensão e declínio, mostrando as épocas históricas em que a poesia esteve maior ou menor, de acordo com os critérios estéticos esboçados por Bueno.

Segundo Tynianov no ensaio a "Evolução literária”, “a função construtiva de um elemento da obra literária como sistema é a possibilidade de entrar em correlação com outros elementos de um mesmo sistema e consequentemente com o sistema inteiro” (1973, p. 108). Logo, algumas obras permanecem mais presentes do que outras no sistema literário. Portanto, sobre a perenidade dos poemas afirma o poeta-historiador que "toda a obra de arte, quando plenamente realizada, vive num presente ubíquo, que é o tempo da grande arte” (BUENO, 2007, p. 11-12). Esse é o critério para a escolha dos poemas para traçar o percurso histórico da poesia no Brasil.

Seguindo na introdução, Bueno sublinha que o ponto de vista adotado para análise da "poesia brasileira é estético, não sociológico ou outros, ainda que não haja obra independente de sua moldura sócio temporal” (2007, p. 12). O caminho escolhido pelo autor revela sua formação intelectual que, a princípio, mostra-se artística. Adiante, ele enfatiza que "este livro trata de arte, não de sociologia da arte, e só o poema como obra de arte, que é o que ele de fato é, lhe interessa” (BUENO, 2007, p. 13).

As primeiras histórias da literatura brasileira tinham como meta principal no século XIX, e até meados do século XX, resolver a questão da nacionalidade do fenômeno literário a partir do seguinte problema: quando a literatura brasileira torna-se autônoma e emancipa-se 
dos influxos literários europeus? Este era o eixo que orientava a maioria das histórias da literatura brasileiras. Os critérios de Bueno são diferentes, uma vez que a questão nacional foi dada como resolvida, outros pressupostos surgiram para nortear o discurso histórico da poesia. Neste caso, a estética é o critério norteador para se examinar historicamente a produção lírica do Brasil. A literatura neste caso é pensada a partir dela mesma e não utilizada como instrumento político para afirmar fatos extraliterários.

A questão que envolve o processo de seleção dos poetas é refletida pelo autor, dado que a produção lírica do Brasil cresce de forma significativa a partir do Parnasianismo. Por conseguinte, o historiador resolve "só tratar, a partir do terceiro quartel do século XIX, de poetas com obra inegavelmente significativa” (BUENO, 2007, p. 13). No período Pós-Guerra o quadro fica enorme e difuso. Na medida em que Bueno se aproxima do tempo presente, a seleção torna-se ainda mais laboriosa, pois os fenômenos literários tornam-se opacos e o próprio tempo exíguo não permite uma seleção plausível. Deste modo, a respeito da contemporaneidade, registra o autor que "buscamos, portanto, no geral, nos limitarmos a um mapeamento genético e estilístico dessa imensa galeria de contemporâneos” (BUENO, 2007, p. 13).

Portanto, o prefácio de Uma história da poesia brasileira revela-se eficiente para o leitor, pois além de o autor apresentar suas premissas teóricas, ele estabelece os critérios que norteiam o seu discurso historiográfico, definindo os conceitos de poesia e História. Concluímos esse tópico com as próprias palavras de Alexei Bueno: “o objetivo deste livro, em resumo, é servir para o leitor como um guia, em um volume, através dos cinco séculos da poesia no Brasil” (2007, p. 14).

\section{Os períodos literários, a crítica e a narrativa}

David Perkins, em História da literatura e narração, reflete sobre a elaboração das classificações literárias e como elas têm sido feitas, dado que “a classificação é fundamental para disciplina de História da Literatura” (1999, p. 30). Como a obra tem como título Uma historia da poesia brasileira, evidentemente que ao elaborar esse arbitrário discurso histórico do percurso poético, uma classificação periódica se torna necessária. Uma vez que, conforme Perkins, “a multiplicidade de objetos deve ser convertida em um número menor de unidades e mais manejáveis, que podem então ser caracterizadas, comparadas, inter-relacionadas, e ordenadas” (1999, p. 30). 
A narrativa e a classificação dos períodos literários, de forma geral, são arquitetadas nas histórias literárias a partir de uma meta, um objetivo a ser alcançado, portanto, ambas são coniventes, do mesmo modo, a crítica. Todos esses elementos se valem para legitimar uma proposta interpretativa para além da descrição histórica dos períodos literários. A propósito das narrativas históricas literárias que almejavam concretizar a autonomia nacional da literatura no Brasil, conforme mencionamos anteriormente, Afrânio Coutinho aponta que

De Wolf a Sílvio Romero, e de José Veríssimo a Ronald de Carvalho, o problema da periodização vincula-se ao conteúdo nacional da literatura, e a história literária é a verificação desse crescente sentimento, a princípio mascarado de nativismo, e cada vez mais tornado consciente até abrolhar em verdadeiro sentimento nacional. (COUTINHO, 2008, p. 29).

Os períodos, a narrativa e a crítica juntos estabeleciam uma organização de leitura orientada do passado, em alguns casos, teleológica. Em outras palavras, o historiador sempre determina o foco da narração. Veremos como esses três elementos: a narrativa, a periodização e a crítica se compõem e se articulam no texto de Alexei Bueno. Somente alguns capítulos foram escolhidos para análise, mas devido à extensão dos mesmos, eles não serão examinados na íntegra, portanto, selecionamos algumas passagens que consideramos importantes para termos um quadro geral da obra.

Toda narrativa tem um início arbitrariamente estabelecido pelo escritor. Nas histórias da literatura também é utilizado um ponto de partida para demarcar o começo da literatura em algum determinado sistema literário. Evidentemente, a construção do início parte de um critério escolhido pelo historiador. Conforme destaca Perkins, "esse momentos inaugurais são convencionais, e histórias da mesma literatura podem escolher diferentes pontos de partida” (1999, p. 10).

No capítulo Na terra Santa Cruz pouco sabida, Bueno institui o início da poesia brasileira, e os seus primórdios são elaborados "claramente a um país, o Brasil histórico, e a uma língua, a portuguesa” (BUENO, 2007, p. 15). Esse critério da língua portuguesa é construído pelo viés do próprio conceito de poesia Ocidental, pois como seria possível encontrar aqui uma produção lírica entre as populações ameríndias? Portanto, o critério da língua e do Brasil recém-frequentado pela Europa é plausível.

Bueno registra que "teve o nosso país a sua verdadeira porta de entrada na poesia universal - e da mais alta -, [...] pela mão de Camões que a encontramos, na oitava 140 do último canto de Os Lusíadas” (BUENO, 2007, p. 15). Essa descrição inicial pela lente da Metrópole mostra um início imponente, a escolha de Camões apresenta o começo de um 
passado literário em grande estilo, para que na sequência registre as produções poéticas em terras brasileiras.

A produção artística jesuítica é o ponto de partida para os princípios da nacionalidade e de se verificar a poesia no Brasil. Neste capítulo de abertura, dois autores recebem espaço para crítica e uma breve biografia. O padre José de Anchieta é quem apresenta o "primeiro poema brasileiro - que é também a primeira epopeia do Novo Mundo - De gestis Mendi de Saa”, escrita em Latim, e, Bento Teixeira com a sua celebre Prosopopeia. Anchieta é analisado a partir do conteúdo semântico dos seus poemas, enquanto Bento Teixeira, além da análise semântica, recebe comentários sobre a sua forma poética. Teixeira é considerado “autor do primeiro poema brasileiro em português” (BUENO, 2007, p. 20). Observa-se na página dezesseis uma ilustre iconografia do frontispício do primeiro poema brasileiro.

No capítulo Barroco nos trópicos, o historiador aponta que após a fase renascentista que cercou o começo da arte verbal no Brasil, uma vez que este foi descoberto no último ano do século XV, estava por terminar, e, “é em pleno barroco, em sua avassaladora força no mundo latino, que se expressarão as primeiras vozes realmente nacionais da poesia brasileira” (BUENO, 2007, p. 21). Interessante observarmos que o critério de nacionalidade é destacado pelo autor desde quando o Brasil é ainda colônia. A história política não é vista como elemento auxiliar para mapear a independência artística nacional, mas a poesia por si mesma já é autônoma pela qualidade de sua produção.

Neste sentido, Bueno vai ao encontro de Coutinho, que salienta: "a nossa literatura foi 'brasileira' desde o primeiro instante, assim como foi brasileiro o homem que no Brasil se afirmou desde o momento em que o europeu aqui pôs o pé e aqui ficou” (2008, p. 32). O historiador poeta parte da premissa teórica de que a arte não se subordina a história política. Deste modo, Bueno também anuncia seu critério de periodização, que podemos depreender como uma “periodização estilística”. Segundo Coutinho, a periodização estilística

\footnotetext{
põe em relevo o caráter estético, a especificidade e autonomia da literatura. Para quem defende esse conceito, a arte é estilo, oriundo da criação ou transformação de formas; o objeto estético, a obra de arte, é um todo, um universo auto-suficiente, com uma forma e uma estrutura, uma autonomia e uma finalidade internas, uma forma significante, bastando-se e existindo por si mesmo, com a sua verdade própria, não se colocando a serviço de nenhum outro valor, não tendo outra função além de sua própria, que é despertar o prazer estético. (COUTINHO, 2008, p. 32).
}

Sendo assim, Alexei Bueno compõe uma história da literatura de ordem estética, na qual os fenômenos literários são contemplados a partir de "manchas estilísticas, sistema de 
normas que não tem limites precisos, mas ao contrário, se imbricam, interpenetram, superpõem” (COUTINHO, 2008, p. 31).

O historiador destaca que Gregório de Matos Guerra é “o primeiro grande poeta do Brasil e o maior do período barroco” (BUENO, 2007, p. 21). Deste modo, o “Boca do inferno" constitui o protagonista deste capítulo, pois ele recebe onze páginas de análise no modelo vida e obra. A sua produção poética é a ascensão da poesia em pleno barroco, os posteriores ou contemporâneos são considerados menores dentro desse período, logo, uma fase de declínio da poesia. Em Gregório de Matos Guerra, a crítica é bem extensa, Bueno destaca que

\begin{abstract}
mas se a face satírica foi a que lhe deu maior celebridade, é preciso lembrar que sua obra se expandia, como a de Quevedo, a todos os gêneros poéticos, o lírico, o amoroso, o religioso, o encomiástico, em todos se encontrando grandes realizações, e com maestria técnica que visivelmente se compraz, virtuosisticamente, em esgotar o infindável arsenal de recursos estilísticos, formais, rítmicos, rímicos, retóricos, da poesia barroca. (Grifos meus) (2007, p. 23-24).
\end{abstract}

A crítica literária de Bueno, conforme se observa acima, algumas vezes, assume um perfil comparatista com os escritores europeus. A literatura comparada, mesmo que em menor grau, é presente na análise da produção poética de Gregório de Matos, dado que Bueno compara em conteúdo a produção do referido escritor com a de Quevedo. No final desse capítulo, temos um breve exame das academias arcádicas fundadas pelos poetas durante o século XVIII.

No capítulo O teatro arcádico, o autor registra que no século XVIII "renasce a prática poética em trajes arcádicos” durante o período do ciclo econômico da mineração no Brasil (BUENO, 2007, p. 37). No período arcádico, o historiador enfatiza que “Marília de Dirceu foi o livro de poesia mais lido e reeditado na língua portuguesa no século XIX” (BUENO, 2007, p. 42). No arcadismo dois poetas mineiros tentaram realizar uma poesia épica. Basílio da Gama com a obra O Uraguai, e Frei José de Santa Rita Durão com a obra O Caramuru. Para Bueno, $O$ Uraguai teve o principal mérito histórico de inserir o índio na poesia brasileira, e $O$ Caramuru narra o descobrimento da Bahia por Diogo Álvares Correia. No entanto, ambas não conseguiram colocar a poesia no patamar de um épico representativo para o sistema literário brasileiro.

No capítulo A festa modernista - o mais extenso da obra - o narrador argumenta que “não há como tratar da poesia modernista do Brasil, sem começarmos por nomes que surgiram num estilo totalmente diverso, mas que se aproximaram ou se converteram à nova 
tendência” (BUENO, 2007, p. 285). Nesse sentido, a periodização estilística agrega os diferentes estilos, até o momento em que estes se convertem em uma dominante artística que caracterize o período literário modernista.

O primeiro autor de vanguarda a ser analisado é Manuel Bandeira e, através da descrição biográfica do mesmo, Bueno comenta sobre os efeitos que os fatos da vida tiveram na sua produção poética. O historiador aponta que "perto dos 18 anos, aconteceu o fato que marcaria toda a sua vida e obra, e seria quase o elemento catalisador da sua poesia, a descoberta de uma tuberculose avançada” (BUENO, 2007, p. 285). A crítica literária nesse momento torna-se imbricada com a história de vida do poeta.

Essa crítica de perfil biográfico surgiu na primeira metade do século XIX, e seu maior representante foi o historiador da literatura francesa Charles Saint Beuve (1804-1868). Beuve com seu método biográfico almejava compreender uma obra a partir da história de vida do autor. Nessa perspectiva, a literatura é explicada por elementos extraliterários, em outras palavras, a classe social do autor, a sua formação educacional, os seus relacionamentos, a sua religião, enfim, tudo isso servia para se comprovar as passagens da vida do escritor na sua obra.

O conhecimento sobre a vida do autor é importante para análise literária, mas sua biografia não dá conta do fenômeno artístico em sua integridade, apenas aponta alguns caminhos interpretativos. Esse tipo de crítica permeia toda obra de Bueno, porém ele não a usa de modo exaustivo, apenas a utiliza na medida em que ela contribua para se examinar determinadas composições poéticas. A propósito de Bandeira, Bueno aponta que “o poema inicial, "Epígrafe”, é quase uma síntese do drama pessoal do autor, inseparável de sua obra” (2007, p. 287).

Uma história da poesia brasileira tem como enredo, conforme a introdução do autor, a ascensão e declínio da poesia brasileira. Em toda a obra, a poesia é narrada nesta perspectiva, alguns autores elevam a poesia numa qualidade ímpar, contribuindo para sua ascensão, já outros a degeneram qualitativamente, produzindo o seu eventual declínio. Isso ocorre tanto entre os períodos, quanto na própria vida dos autores, uma vez que a sua produção poética adquire momentos, ora elevados, ora decadentes.

$\mathrm{Na}$ análise de Cecília Meireles, a poesia nacional adquiriu um estatuto épico de qualidade, ascendeu no modernismo, visto que Mar absoluto e outros poemas, de 1945, representa o apogeu de sua poesia especificamente lírica, e, o Romanceiro da Inconfidência, a sua obra prima. Adiante, Bueno sublinha que na história da poesia brasileira esta obra é a que mais se aproxima de um épico nacional (BUENO, 2007, p. 319-322). 
Passado o período do Modernismo brasileiro, a poesia irá se abrir em diversas tendências e movimentos. No capítulo Dissoluções e derivações do modernismo, o autor aponta que "a poesia brasileira se abriu num vasto leque sincrético que segue até hoje” (BUENO, 2007, p. 356). Portanto, são analisados brevemente diversos poetas a partir dos seus estilos particulares ou pelas tendências vanguardistas do período. Sublinha Bueno que

\begin{abstract}
a geração de 45 apareceu como uma natural reação às duas décadas de hegemonia estética do primeiro Modernismo entre nós. Como sempre ocorre em absolutamente todos os movimentos literários, a liberdade de 1922 se transformara numa nova camisa de força, o verso livre se ressentia de um uso excessivo e desvalorizador, a ironia, a irreverência e o poema-piada começavam a perder significado depois da hecatombe sem precedentes da Segunda Guerra. $\mathrm{O}$ ano que deu nome à geração fora marcado pelo fim do conflito, pela queda da longa ditadura estadonovista, pela morte de Mário de Andrade. Pregando um retorno às formas fixas, com uma tendência bastante marcante, entre alguns dos seus membros, a uma visão menos materialista da realidade que a de muitos dos modernistas de primeira hora, o movimento cometeu os excessos de todos eles na defesa de suas postulações e no ataque a recente escola hegemônica. (BUENO, 2007, p. 365).
\end{abstract}

Compreender a emergência e o valor das vanguardas a partir da década de 50 é um dos objetivos do historiador. Bueno aponta que as vanguardas do século XX, geralmente foram estabelecidas a partir da concepção histórica do progresso, na qual, ciclos artísticos e formas primárias da lírica são substituídos por novos movimentos, em geral, destituídos de qualidade estética. A título de exemplo dessa tendência, destaca o autor que o Concretismo, lançado em 1956, “considerava acabado o ciclo histórico do verso” (BUENO, 2007, p. 382). O maior problema dessa vanguarda é que o Concretismo é considerado como um ramo das artes visuais e não especificamente da literatura, portanto, a poesia decai nesse processo. Situação distinta é da Poesia Práxis, pois este se define por ser um movimento de vanguarda que se insere realmente no domínio da poesia (BUENO, 2007, p. 383).

No último capítulo No agora e aqui pouco sabido, o narrador aponta que o “julgamento de qualquer arte sem distanciamento temporal é das ações mais problemáticas, exceto nos casos de escandalosa qualidade ou escandalosa ausência dela”. Este é o critério que o autor utiliza para se debruçar no tempo contemporâneo, pois afinal, apenas “o tempo e a morte são os faxineiros do palco artístico”, uma vez que são estes que elegem a arte poética plenamente realizada (BUENO, 2007, p. 396).

Alexei Bueno argumenta que nas últimas três décadas do século $\mathrm{XX}$, a poesia foi sendo fragmentada de forma crescente, quase se tornando em vertentes particularizadas por cada poeta. Do mesmo modo, o autor chama a atenção para o desaparecimento dos poetas 
vinculados a outras profissões, pois atualmente, os escritores estão intimamente ligados ao ambiente universitário ou são professores de literatura. Outro aspecto salientado por Bueno é que a poesia contemporânea está se aproximando mais da música popular.

\section{Considerações finais}

Este breve exame de Uma história poesia brasileira, de Alexei Bueno, permite a constatação de algumas hipóteses:

1) Um dos aspectos teóricos da obra é o fato de o historiador não se instrumentalizar das recentes teorias historiográficas que pensam a produção das histórias literárias, sobretudo aquelas de estudos sociológicos, interdisciplinares e por uma definição pragmática da literatura. A própria Estética da Recepção ressaltou a literatura a partir dos efeitos no leitor. Alexei Bueno se baseia em teorias esteticistas e imanentista para depreender o fenômeno literário.

2) Observa-se, pelo conteúdo reflexivo e o léxico utilizado nessa produção historiográfica, que esta se destina a um público específico, isto é, aos professores de literatura e leitores de poesia. A crítica literária que subjaz a obra de Bueno é restrita a um grupo de leitores que compreendem os conceitos que permeiam a produção poética. Portanto, ela não é destinada, mesmo que tenha essa pretensão, a um público amplo, heterogêneo.

3) A narrativa, mesmo não elucidando as características dos períodos estéticos, ela se vale de uma perspectiva histórica linear, e realiza uma concatenação entre as obras, mediante o recurso da "periodização estilística”. Logo, promove um encadeamento imbricado entre obras, levando em conta produções distintas de um mesmo período dominante. As datas de nascimento e de morte dos poetas servem como fio condutor temporal para orientação do leitor.

4) Mesmo a obra não tendo um ponto de vista sociológico ou histórico, ela é composta por concisas biografias que se tornam instrumentos para compreensão de alguns poemas específicos dos poetas. Alguns recebem maior espaço para biografia, outros nem tanto, depende de sua produção poética e/ou precocidade artística. Como também, o historiador utiliza retratos dos poetas, método divulgado na França a partir dos portraits de Sainte-Beuve que enfatizava a história do indivíduo.

5) Em geral, a crítica literária em Uma história da poesia brasileira pode ser depreendida como de vertente formalista. A crítica formalista recusa os métodos de 
interpretações extraliterárias do texto. A filosofia, a sociologia, a psicologia, etc. não servem de ponto de partida para a abordagem da obra literária, pois o importante é analisar o princípio da organização textual que produz o efeito estético.

6) Uma história da poesia brasileira tem o mérito de constituir uma maior presença da lírica no âmbito da história da literatura brasileira. Alexei Bueno forma, a partir dessa obra, uma memória da poesia brasileira, um panorama que aponta para a necessidade de se pensar e historiar o gênero durante seus cinco séculos de produção.

\section{Referências}

BUENO, Alexei. Uma história da poesia brasileira. Rio de Janeiro: G. Ermakoff Casa Editorial, 2007.

BARRENTO, João. “O regresso de Clio? Situações e aporias da história literária”. In: História literária: problemas e perspectivas. Lisboa: Apáginastantas, 1986.

COUTINHO, Afrânio. Conceito de literatura brasileira. 2 Ed. Petrópolis, Rio de Janeiro: Vozes, 2008.

JAMESON, Fredric. Pós-modernismo: a lógica cultural do capitalismo tardio. São Paulo: Ática, 1997.

PERKINS, David. “História da literatura e narração”. In: Cadernos do Centro de Pesquisas Literárias da PUCRS. Porto Alegre, v. 3, n. 1, mar. 1999. Série Traduções.

SOUZA, Roberto Acízelo de. Formação da teoria da literatura. Inventário de pendências e protocolo de intenções. Rio de Janeiro: Ao Livro Técnico; Niterói: Universidade Federal Fluminense, 1987.

TYNIANOV, J. "Da evolução literária”. In: EIKHENBAUM, B. Teoria da literatura: formalistas russos. Porto Alegre: Globo, 1973. 